\section{JURNAL EKONOMI EFEKTIF}

ISSN : $2622-8882$, E-ISSN : 2622-9935

Jurnal Ekonomi Efektif, Vol. 3, No. 3, April 2021

@Prodi Manajemen Fakultas Ekonomi Universitas

Pamulang

\title{
PENGARUH PROFITABILITAS DAN LIQUIDITAS TERHADAP MODAL KERJA PADA PT. FASTFOOD INDONESIA, TBK PERIODE 2012-2019
}

\author{
Arif Hidayat \\ Universitas Pamulang, Tangerang Selatan, Banten, Indonesia \\ dosen02519@unpam.ac.id
}

Manuskrip: Mar-2021 Ditinjau: Mar-2021; Diterima: Mar-2021; Online: Apr-2021; Diterbitkan: Apr-2021

\begin{abstract}
ABSTRAK
Penelitian ini bertujuan untuk mengetahui Pengaruh Profitabilitas dan Likuiditas Terhadap Modal Kerja Pada PT. Fastfood Indonesia, Tbk Periode 2012-2019. Metode yang digunakan adalah explanatory research. Teknik analisis menggunakan analisis statistik dengan pengujian regresi, korelasi, determinasi dan uji hipotesis. Hasil penelitian ini Return on Invesment berpengaruh signifikan terhadap Net Working Capital sebesar 64,8\%, uji hipotesis diperoleh nilai $\mathrm{t}$ hitung $>\mathrm{t}$ tabel atau $(3,326>2,447)$. Current Ratio berpengaruh signifikan terhadap Net Working Capital sebesar 96,8\%, uji hipotesis diperoleh nilai $\mathrm{t}$ hitung $>\mathrm{t}$ tabel atau $(13,569>2,447)$. Return on Invesment dan Current Ratio secara simultan berpengaruh signifikan terhadap Net Working Capital diperoleh persamaan regresi $\mathrm{Y}=1,450+0,372 \mathrm{X} 1+$ 0,847X2 dan nilai determinasi sebesar 97,0\%, uji hipotesis diperoleh nilai $\mathrm{F}$ hitung $>\mathrm{F}$ tabel atau $(81,438>5,410)$.
\end{abstract}

Kata Kunci: Profitabilitas, Likuiditas, Modal Kerja.

\begin{abstract}
This study aims to determine the effect of profitability and liquidity on working capital at PT. Fast food Indonesia, Tbk for the period 2012-2019. The method used is explanatory research. The analysis technique uses statistical analysis with regression testing, correlation, determination and hypothesis testing. The results of this study, Return on Investment has a significant effect on Net Working Capital by 64.8\%. Hypothesis testing obtained the value of $t$ count> t table or (3.326> 2.447). Current Ratio has a significant effect on Net Working Capital of $96.8 \%$, hypothesis testing obtained t value > t table or (13.569> 2.447). Return on Investment and Current Ratio simultaneously have a significant effect on Net Working Capital, the regression equation is $Y=1,450+0.372 X 1+0.847 X 2$ and a determination value of $97.0 \%$, hypothesis testing obtained the value of $F$ count $>F$ table or $(81,438>5,410)$.
\end{abstract}

\section{Keywords: Profitability, Liquidity, Working Capital.}




\section{PENDAHULUAN}

\section{A. Latar Belakang Masalah}

Pada umumnya suatu perusahaan didirikan dengan tujuan untuk memperoleh laba. Laba merupakan hasil yang menguntungkan atas usaha yang dilakukan perusahaan pada suatu periode tertentu. Dengan laba ini dapat digunakan perusahaan untuk tambahan pembiayaan dalam menjalankan usahanya, dan yang terpenting adalah sebagai alat untuk menjaga kelangsungan hidup perusahaan.

Laba hanya bisa diperoleh dengan adanya kinerja yang baik dari perusahaan itu sendiri. Untuk itu penilaian terhadap perusahaan sangat penting dan bermanfaat, baik bagi perusahaan, maupun bagi pihak luar perusahaan yang berkepentingan terhadap perusahaan yang bersangkutan. Bagi suatu perusahaan, kinerja dapat digunakan sebagai alat ukur dalam menilai keberhasilan usahanya, juga dapat digunakan sebagai bahan pertimbangan dalam pengambilan keputusan dan perencanaan dimasa yang akan datang. Sedangkan bagi pihak luar perusahaan dapat digunakan sebagai bahan pertimbangan dalam pengambilan keputusan ekonomi terhadap perusahaan yang bersangkutan.

Untuk mengetahui kinerja suatu perusahaan dapat dilihat dari aspek keuangan dan aspek non keuangan. Dari aspek non-keuangan, kinerja dapat diketahui dengan cara, mengukur tingkat kejelasan pembagian fungsi dan wewenang dalam struktur organisasinya, mengukur tingkat kualitas sumber daya yang dimilikinya, mengukur tingkat kesejahteraan pegawai dan karyawannya, mengukur kualitas produksinya, mengukur tingkat kepercayaan masyarakat terhadap perusahaan serta dengan mengukur tingkat kepedulian perusahaan terhadap lingkungan sosisal sekitarnya.

Analisis keuangan yang sering digunakan untuk menilai kinerja suatu perusahaan adalah analisis rasio keuangan. Dengan analisis rasio keuangan akan dapat diketahui tingkat likuiditas, tingkat profitabilitas dan Modal Kerja perusahaan. Dengan mengetahui tingkat suatu perubahan, maka akan dapat diketahui kemampuan perusahaan dalam memenuhi kewajiban jangka pendeknya dengan jaminan harta lancarnya. Tingkat likuiditas ini sangat berguna bagi perusahaan khususnya kreditur yang memberikan kredit jangka pendek. Pada tingkat profitabilitas, akan dapat diketahui kemampuan perusahaan dalam memenuhi semua kewajibannya dengan jaminan harta yang dimilikinya, tingkat profitabilitas ini sangat berguna bagi kreditur, untuk memberikan kredit jangka pendek maupun jangka panjang. Jadi dengan mengetahui tingkat likuiditas, profitabilitas dan modal kerja suatu perusahaan, maka akan dapat diketahui keadaan perusahaan yang bersangkutan, apakah perusahaan tersebut baik atau buruk sehingga dapat diperkirakan tentang kelangsungan hidup perusahaan yang bersangkutan.

Rasio menggambarkan suatu hubungan atau pertimbangan atau perimbangan (mathematical relationship) antara suatu terntu dengan jumlah yang lain, dan dengan menggunakan alat analisa beruapa rasio ini akan dapat menjelaskan atau memberi gambaran kepada penganalisa tentang baik atau buruknya keadaan atau posisi keuangan suatu perusahaan terutama apabila angka rasio tersebut dibandingkan dengan angka rasio pembanding yang digunakan sebagai standar.

Franchising (pewaralabaan) pada hakekatnya adalah sebuah konsep pemasaran dalam rangka memperluas jaringan usaha secara cepat. Dengan demikian, franchising bukanlah sebuah alternatif melainkan salah satu cara yang sama kuatnya, sama strategisnya dengan cara konvensional dalam mengembangkan usaha. Bahklan sistem franchise dianggap memiliki banyak kelebihan terutama menyangkut pendanaan, SDM dan manajemen, kecuali kerelaan pemilik merek untuk berbagi dengan pihak lain. Franchising juga dikenal sebagai jalur distribusi yang sangat efektif untuk mendekatkan produk kepada konsumennya melalui tangan-tangan franchiser. 
Di Indonesia franchise dikenal sejak tahun 70an ketika masuknya Shakey Pisa, KFC, Swensen,dan Burger King, yang perkembangannya terlihat sangat pesat dimulai sekitar 1995. Data Deperindag pada 1997 mencatat sekitar 259 perusahaan penerima franchise di Indonesia tapi usaha franchise ini mengalami kemerosotan Ketika terjadi krisis moneter. Para penerima franchise asing terpaksa menutup usahanya karena nilai rupiah yang terperosok sangat dalam. Hingga tahun 2000, franchise asing masih menunggu untuk masuk ke Indonesia. Hal itu disebabkan kondisi ekonomi dan politik yang belum stabili ditandai dengan perseteruan para elit politik. Barulah pada 2003, usaha franchise di tanah air mengalami perkembangan yang sangat pesat

Perkembangan bisnis waralaba atau franchise saat ini memicu pertumbuhan ekonomi yang sehat dan membuka kesempatan lapangan kerja baru. Serta mempermudah peluang pengadaan kesempatan bisnis kepada khalayak luas.

Berikut ini gambaran rasio Profitabilitas, Likuiditas dan Modal Kerja perusahaan periode 2012-2019 sebagai berikut:

Tabel 1. Rasio Keuangan PT Fast Food Indonesia Tbk Periode 2012-2016

\begin{tabular}{|c|c|c|c|}
\hline Tahun & ROI (\%) & CR (\%) & NWC (\%) \\
\hline 2012 & $0.1156 \%$ & $1.2497 \%$ & $0.4392 \%$ \\
\hline 2013 & $0.0771 \%$ & $1.1961 \%$ & $0.4742 \%$ \\
\hline 2014 & $0.0545 \%$ & $1.2932 \%$ & $0.3922 \%$ \\
\hline 2015 & $0.0382 \%$ & $0.8274 \%$ & $0.8035 \%$ \\
\hline 2016 & $0.0132 \%$ & $0.8176 \%$ & $0.7005 \%$ \\
\hline 2017 & $0.1122 \%$ & $1.2755 \%$ & $0.3775 \%$ \\
\hline 2018 & $0.0354 \%$ & $0.8354 \%$ & $0.7653 \%$ \\
\hline 2019 & $0.0255 \%$ & $0.8275 \%$ & $0.7686 \%$ \\
\hline
\end{tabular}

Berdasarkan data pada tabel di atas dapat diketahui Rasio Profitabilitas (ROI), Rasio Likuiditas (CR) dan Modal Kerja (NWC) perusahaan. Dimulai dari nilai ROI perusahaan yang mengalami penurunan setiap tahunnya, didapat angka terkecil di tahun 2016 sebesar $0,0132 \%$.

CR pada perusahaan mengalami fluktuasi didapat angka terkecil tahun 2016 yang hanya mampu mencapai $0,81 \%$ dan nilai paling tinggi di tahun 2014 sebesar 1,29\%.

NWC perusahaan juga mengalami fluktuasi didapat nilai terkecil di tahun 2017 sebesar 0,377\% dan didapat angka terbesar di tahun 2015 sebesar 0,803\%. Dari data laporan keuangan perusahaan dapat diketahui angka rasio keuangan yang mana pada penelitian ini, peneliti menggunakan rasio Profitabilitas fokus pada Return on Invesment (ROI), rasio Likuiditas fokus pada Current Ratio (CR), dan Modal Kerja (NWC).

Berdasarkan data dan uraian di atas, maka penulis tertarik untuk melakukan penelitian dengan judul laporan akhir yang di susun penulis adalah: "Pengaruh Profitabilitas dan Likuiditas Terhadap Modal Kerja PT. Fastfood Indonesia, Tbk.

\section{B. Rumusan Masalah}

1. Adakah pengaruh secara parsial antara Return on Invesment terhadap Net Working Capital pada PT. Fastfood Indonesia, Tbk?.

2. Adakah pengaruh secara parsial antara Current Ratio terhadap Net Working Capital pada PT. Fastfood Indonesia, Tbk ?.

3. Adakah pengaruh secara simultan antara Return on Invesment dan Current Ratio terhadap Net Working Capital pada PT. Fastfood Indonesia, Tbk?. 


\section{Tujuan Penelitian}

1. Untuk mengetahui pengaruh secara parsial antara Return on Invesment terhadap Net Working Capital pada PT. Fastfood Indonesia, Tbk.

2. Untuk mengetahui pengaruh secara parsial antara Current Ratio terhadap Net Working Capital pada PT. Fastfood Indonesia, Tbk.

3. Untuk mengetahui pengaruh secara simultan antara Return on Invesment dan Current Ratio terhadap Net Working Capital pada PT. Fastfood Indonesia, Tbk.

\section{METODE PENELITIAN}

\section{Populasi}

Populasi dalam penelitian ini laporan keuangan PT. Fastfood Indonesia, Tbk selama 8 tahun

\section{Sampel}

Teknik pengambilan sampling dalam penelitian ini adalah samplel jenuh, dimana semua anggota populasi dijadikan sebagai sampel. Dengan demikian sampel dalam penelitian ini laporan keuangan PT. Fastfood Indonesia, Tbk selama 8 tahun.

\section{Jenis Penelitian}

Jenis penelitian yang dipakai adalah asosiatif, dimana tujuannya adalah untuk mengetahui mencari keterhubungan antara variabel independen terhadap variabel dependennya

\section{Metode Analisis Data}

Dalam menganalisis data digunakan uji validitas, uji reliabilitas, analisis regresi linier sederhana, koefisien korelasi, koefisien determinasi dan uji hipotesis.

\section{HASIL PENELITIAN DAN PEMBAHASAN}

\section{Analisis Deskriptif}

Pada pengujian ini digunakan untuk mengetahui besarnya persentase minimum dan maksimum, persentase rata-rata dan standar deviasi dari masing-masing variabel. Adapun hasilnya sebagai berikut:

Tabel 2. Hasil Analisis Descriptive Statistics

\section{Descriptive Statistics}

\begin{tabular}{lr|r|r|r|r} 
& $\mathrm{N}$ & Minimum & Maximum & Mean & Std. Deviation \\
\hline Return on Invesment (X1) & 8 & .01 & .12 & .0590 & .03890 \\
\hline Current Ratio $(\mathrm{X} 2)$ & 8 & .82 & 1.29 & 1.0403 & .22978 \\
\hline Net Working Capital $(\mathrm{Y})$ & 8 & .38 & .80 & .5901 & .18549 \\
\hline Valid N (listwise) & 8 & & & &
\end{tabular}

Return on Invesment diperoleh nilai minimum sebesar $0,01 \%$ dan nilai maximum $0,12 \%$ dengan rata-rata sebesar $0,059 \%$ dengan standar deviasi $0,389 \%$.

Current Ratio diperoleh nilai minimum sebesar 0,82\% dan nilai maximum 1,29\% dengan rata-rata sebesar 1,040\% dengan standar deviasi 0,229\%.

Net Working Capital diperoleh varians minimum sebesar $0,38 \%$ dan nilai maximum $0,80 \%$ dengan rata-rata sebesar $0,59 \%$ dengan standar deviasi $0,185 \%$.

\section{Analisis Verifikatif.}

Pada analisis ini dimaksudkan untuk mengetahui pengaruh variabel independen terhadap variabel dependen. Adapun hasil pengujian sebagai berikut:

\section{a. Analisis Regresi Linier Berganda}

Uji regresi ini dimaksudkan untuk mengetahui perubahan variabel dependen 
jika variabel independen mengalami perubahan. Adapun hasil pengujiannya sebagai berikut:

Tabel 3. Hasil Pengujian Regresi Liner Berganda

Coefficients ${ }^{a}$

Unstandardized $\quad$ Standardized

Coefficients Coefficients

\begin{tabular}{|c|c|c|c|c|c|}
\hline Model & B & Std. Error & Beta & $\mathrm{t}$ & Sig. \\
\hline 1 (Constant) & 1.450 & .090 & & 16.138 & .000 \\
\hline Return on Invesment (X1) & .372 & .681 & .078 & .546 & .609 \\
\hline Current Ratio (X2) & .847 & .115 & -1.050 & 7.351 & .001 \\
\hline
\end{tabular}

a. Dependent Variable: Net Working Capital (Y)

Berdasarkan hasil pengujian pada tabel di atas, diperoleh persamaan regresi $\mathrm{Y}$ $=1,450+0,372 \mathrm{X} 1+0,847 \mathrm{X} 2$. Dari persamaan tersebut dijelaskan sebagai berikut:

1) Konstanta sebesar 1,450 diartikan jika Return on Invesment dan Current Ratio tidak ada, maka telah terdapat nilai Net Working Capital sebesar 1,450 point.

2) Koefisien regresi Return on Invesment sebesar 0,372, angka ini positif artinya setiap ada peningkatan Return on Invesment sebesar 0,372 maka Net Working Capital juga akan mengalami peningkatan sebesar 0,372 point.

3) Koefisien regresi Current Ratio sebesar 0,847, angka ini positif artinya setiap ada peningkatan Current Ratio sebesar 0,847 maka Net Working Capital juga akan mengalami peningkatan sebesar 0,847 point.

\section{b. Analisis Koefisien Determinasi}

Analisis koefisien determinasi dimaksudkan untuk mengetahui besarnya persentase pengaruh dari variabel independen terhadap variabel dependen baik secara parsial maupun simultan. Adapun hasil pengujian sebagai berikut:

Tabel 4. Hasil Pengujian Koefisien Determinasi Return on Invesment Terhadap Net Working Capital.

Model Summary

\begin{tabular}{ll|r|r|r} 
Model & $\mathrm{R}$ & $\mathrm{R}$ Square & Adjusted R Square & \multicolumn{2}{c}{ Std. Error of the Estimate } \\
\hline 1 & $.805^{\mathrm{a}}$ & .648 & .590 & .11881
\end{tabular}

a. Predictors: (Constant), Return on Invesment (X1)

Berdasarkan hasil pengujian diperoleh nilai determinasi sebesar 0,648 artinya Return on Invesment memiliki kontribusi pengaruh sebesar $64,8 \%$ terhadap Net Working Capital.

Tabel 5. Hasil Pengujian Koefisien Determinasi Current Ratio Terhadap Net Working Capital.

Model Summary

\begin{tabular}{lr|r|r|r} 
Model & R & R Square & Adjusted R Square & Std. Error of the Estimate \\
\hline 1 & $.984^{\mathrm{a}}$ & .968 & .963 & .03559 \\
\hline
\end{tabular}

a. Predictors: (Constant), Current Ratio (X2)

Berdasarkan hasil pengujian diperoleh nilai determinasi sebesar 0,968 artinya Current Ratio memiliki kontribusi pengaruh sebesar 96,8\% terhadap Net Working Capital.

Tabel 6. Hasil Pengujian Koefisien Determinasi Return on Invesment dan Current Ratio Terhadap Net Working Capital

Model Summary

\begin{tabular}{lr|r|r|r} 
Model & R & R Square & Adjusted R Square & Std. Error of the Estimate \\
\hline 1 & $.985^{\mathrm{a}}$ & .970 & .958 & .03788 \\
\hline
\end{tabular}


a. Predictors: (Constant), Current Ratio (X2), Return on Invesment (X1)

Berdasarkan hasil pengujian diperoleh nilai determinasi sebesar 0,970 artinya Return on Invesment dan Current Ratio secara simultan memiliki kontribusi pengaruh sebesar 97,0\% terhadap Net Working Capital, sedangkan sisanya sebesar 3,0\% dipengaruhi faktor lain.

\section{c. Uji Hipotesis}

\section{Uji hipotesis Parsial (Uji t)}

Pengujian hipotesis dengan uji t digunakan untuk mengetahui hipotesis parsial mana yang diterima.

Tabel 7. Hasil Uji Hipotesis Return on Invesment Terhadap Net Working Capital..

\section{Coefficients $^{\mathrm{a}}$}

\begin{tabular}{|c|c|c|c|c|c|c|}
\hline \multirow{2}{*}{\multicolumn{2}{|c|}{ Model }} & \multicolumn{2}{|c|}{$\begin{array}{l}\text { Unstandardized } \\
\text { Coefficients }\end{array}$} & \multirow{2}{*}{$\begin{array}{c}\text { Standardized } \\
\text { Coefficients } \\
\text { Beta } \\
\end{array}$} & \multirow[b]{2}{*}{$\mathrm{t}$} & \multirow[b]{2}{*}{ Sig. } \\
\hline & & $\mathrm{B}$ & Std. Error & & & \\
\hline & (Constant) & .817 & .080 & & 10.208 & .000 \\
\hline & Return on Invesment (X1) & 3.840 & 1.154 & -.805 & 3.326 & .016 \\
\hline
\end{tabular}

a. Dependent Variable: Net Working Capital (Y)

Berdasarkan hasil pengujian pada tabel di atas, diperoleh nilai t hitung $>\mathrm{t}$ tabel atau $(3,326>2,447)$, dengan demikian terdapat pengaruh yang signifikan atara Return on Invesment terhadap Net Working Capital.

Tabel 8. Hasil Uji Hipotesis Current Ratio Terhadap Net Working Capital.

\section{Coefficients $^{\text {a }}$}

Unstandardized

Coefficients

\begin{tabular}{|c|c|c|c|c|c|}
\hline Model & $\mathrm{B}$ & Std. Error & Beta & $\mathrm{t}$ & Sig. \\
\hline $\begin{array}{ll}1 & \text { (Constant) }\end{array}$ & 1.417 & .062 & & 22.778 & .000 \\
\hline Current Ratio (X2) & .794 & .059 & -.984 & 13.569 & .000 \\
\hline
\end{tabular}

a. Dependent Variable: Net Working Capital (Y)

Berdasarkan hasil pengujian pada tabel di atas, diperoleh nilai $t$ hitung $>\mathrm{t}$ tabel atau $(13,569>2,447)$, dengan demikian terdapat pengaruh yang signifikan atara Current Ratio terhadap Net Working Capital.

\section{Uji Hipotesis Simultan (Uji F)}

Pengujian hipotesis dengan uji $\mathrm{F}$ digunakan untuk mengetahui hipotesis simultan yang mana yang diterima.

Tabel 9. Hasil Uji Hipotesis Return on Invesment dan Current Ratio Terhadap Net Working Capital

\begin{tabular}{|c|c|c|c|c|c|c|}
\hline \multicolumn{7}{|c|}{ ANOVA ${ }^{\mathrm{a}}$} \\
\hline Model & & Sum of Squares & df & $\begin{array}{l}\text { Mean } \\
\text { Square }\end{array}$ & $\mathrm{F}$ & Sig. \\
\hline \multirow[t]{3}{*}{1} & Regression & .234 & 2 & .117 & 81.438 & $.000^{\mathrm{b}}$ \\
\hline & Residual & .007 & 5 & .001 & & \\
\hline & Total & 241 & 7 & & & \\
\hline
\end{tabular}

Berdasarkan hasil pengujian pada tabel di atas, diperoleh nilai $\mathrm{F}$ hitung $>\mathrm{F}$ tabel atau $(81,438>5,410)$, dengan demikian terdapat pengaruh yang signifikan atara Return on Invesment dan Current Ratio terhadap Net Working Capital. 


\section{PEMBAHASAN HASIL PENELITIAN}

\section{Pengaruh Return on Invesment Terhadap Net Working Capital}

Berdasarkan hasil analisis variabel Return on Invesment berpengaruh signifikan terhadap Net Working Capital dengan kontribusi pengaruh sebesar 64,8\%. Pengujian hipotesis diperoleh nilai $\mathrm{t}$ hitung $>\mathrm{t}$ tabel atau $(3,326>2,447)$. Dengan demikian terdapat pengaruh signifikan antara Return on Invesment terhadap Net Working Capital.

\section{Pengaruh Current Ratio Terhadap Net Working Capital}

Berdasarkan hasil analisis variabel Current Ratio berpengaruh signifikan terhadap Net Working Capital dengan kontribusi pengaruh sebesar 96,8\%. Pengujian hipotesis diperoleh nilai $t$ hitung $>\mathrm{t}$ tabel atau $(13,569>2,447)$. Dengan demikian terdapat pengaruh signifikan antara Current Ratio terhadap Net Working Capital.

\section{Pengaruh Return on Invesment dan Current Ratio Terhadap Net Working Capital}

Berdasarkan hasil analisis variabel Return on Invesment dan Current Ratio secara simultan berpengaruh signifikan terhadap Net Working Capital dengan diperoleh persamaan regresi $\mathrm{Y}=1,450+0,372 \mathrm{X} 1+0,847 \mathrm{X} 2$, dengan kontribusi pengaruh sebesar 97,0\%. Pengujian hipotesis diperoleh nilai $\mathrm{F}$ hitung $>\mathrm{F}$ tabel atau $(81,438>$ 5,410). Dengan demikian terdapat pengaruh signifikan antara Return on Invesment dan Current Ratio terhadap Net Working Capital.

\section{PENUTUP}

\section{Kesimpulan}

a. Return on Invesment berpengaruh signifikan terhadap Net Working Capital dengan kontribusi pengaruh sebesar $64,8 \%$. Uji hipotesis diperoleh nilai t hitung $>\mathrm{t}$ tabel atau $(3,326>2,447)$.

b. Current Ratio berpengaruh signifikan terhadap Net Working Capital dengan kontribusi pengaruh sebesar 96,8\%. Uji hipotesis diperoleh nilai t hitung $>\mathrm{t}$ tabel atau $(13,569>2,447)$.

c. Return on Invesment dan Current Ratio berpengaruh signifikan terhadap Net Working Capital dengan kontribusi pengaruh sebesar 97,0\%. Uji hipotesis diperoleh nilai $\mathrm{F}$ hitung > F tabel atau $(81,438>5,410)$.

\section{Saran}

a. Dari hasil perhitungan rasio Profitabilitas perusahaan cenderung mengalami penurunan di setiap tahunnya, maka sebaiknya pengeluaran biaya operasional lebih diminimalisi agar mendapat keuntungan bersih yang lebih besar lagi.

b. Likuiditas perusahaan mengalami penurunan (berfluktuasi), maka aktiva lancar harus ditingkatkan agar perusahaan mampu membayar kewajibannya baik jangka pendek maupun jangka panjang.

c. Manajemen harus lebih jeli menganalisa tentang profitabilitas dan likuiditas perusahaan demi pemenuhan modal kerja PT Fast Food Indonesia Tbk di masa yang akan datang.

d. Untuk penelitian selanjutnya, interval periode penelitian agar ditambah melebihi interval tahun dalam penelitian sehingga memberikan sampel yang lebih banyak serta hasil yang lebih akurat. 


\section{DAFTAR PUSTAKA}

Agus Harjito \& Martono, (2010) "Manajemen Keuangan" Yogyakarta: Penerbit Ekonisia. Agus Sartono. (2010). "Manajemen Keuangan Toeri dan Aplikasi", Edisi keempat, Yogyakarta: Penerbit BPFE.

Algifari. (2015). "Analisis Regresi untuk Bisnis dan Ekonomi”. Yogyakarta: BPFE.

Arikunto, Suharsimi (2014). "Prosedur Penelitian Suatu Pendekatan Praktek". Jakarta: Rineka Cipta.

Bambang Riyanto, (2011). "Dasar-dasar Pembelanjaan Perusahaan". Edisi ke empat, BPFE Yogyakarta.

Fahmi, Irham (2012), "Pengantar Manajemen Keuangan" Cetakan pertama. Bandung: Penerbit Alfabeta.

Fahmi, Irham. 2011 "manajemen kinerja, Teori dan Aplikasi". Bandung: Cetakan kedua, Alfabeta, CV.

Harahap, Sofyan Syafri. 2008. Analisis Kritis atas Laporan Keuangan. Jakarta: PT Raja Grafindo Persada

Hidayat, A., \& Sunarsi, D. (2020). Faktor-Faktor Yang Mempengaruhi Dana Pihak Ketiga Dan Dampaknya Terhadap Profitabilitas (Survey Pada Bpr Syariah Di Jawa Barat Tahun 2014-2017). Jurnal Proaksi, 7(1), 54-65.

Imam Ghozali (2017). “Aplikasi Analisis Multivariate Dengan Program SPSS”. Edisi Kelima. Semarang: Badan Penerbit Undip.

Istijanto (2014) "Riset Sumber Daya Manusia". Jakarta: PT. Gramedia Pustaka

Jasmani, J. (2018). Pengaruh Kinerja Keuangan Terhadap Harga Saham (Analisis Pada Perusahaan Property dan Real Estate Yang Go Public di Bursa Efek Indonesia. Jurnal Akuntansi Indonesia, 12(2).

Jasmani, J. (2019). The Effect of Liquidity and Working Capital Turnover on Profitability at PT. Sumber Cipta Multiniaga, South Jakarta. PINISI Discretion Review, 3(1), 2938.

Kardiman, "Prinsip-Prinsip Akuntansi 1", cetakan kedua, Yudhistira, Yogyakarta, 2007.

Kasmir (2010), “Analisis Laporan keuangan”, penerbit raja grafindo persada, Jakarta

Kasmir. (2012) "Pengantar Manajemen Keuangan", Edisi Pertama, Cetakan kedua, Jakarta: Prenada Media.

Kuncoro, Mudrajad, "Metode Kuantitatif Teori dan Aplikasi Untuk Bisnis dan Ekonomi". Edisi ketiga, UPP STIM YKPN, Yogyakarta, 2007.

Martono dan Agus Harjito, (2011). "Manajemen Keuangan”, Jakarta: Penerbit Ekonisia.

Munawir (2010), “Analisis Laporan Keuangan”, Edisi Ke Empat, Penerbit Liberty, Yogyakarta.

Rifuddin, B., Ilham, D., \& K, N. (2020). Academic Services in Islamic Education Management Study Program: The Actualization of the Basic Values of the State Civil Apparatus at IAIN Palopo. International Journal of Asian Education, 1(2), 8194. https://doi.org/10.46966/ijae.v1i2.34

Santoso, Singgih (2015). "Menguasai Statistik Multivariat". Jakarta: PT Elex Media Komputindo.

Sawir, (2015). "Analisis Kinerja Keuangan dan Perencanaan Keuangan Perusahaan", Cetakan ketiga, Jakarta: Penerbit PT. Gramedia Pustaka Utama.

Sugiyarso, G. dan F. Winarni (2015). "Manajemen Keuangan (Pemahaman Laporan Keuangan, Pengelolaan Aktiva, Kewajiban dan Modal serta Pengukuran

Sugiyono (2017), "Metode Penelitian Administrasi : dilengkapi dengan Metode R \& D". Bandung: Alfabeta 